ЖУЧЕНКО О. С., к.т.н., доцент, ПРИХОДЬКО С. І., д.Т.н., професор, ШТОМПЕЛЬ М.А., к.т.н., доцент (Український державний університет залізничного транспорту)

\title{
Особливості програмної реалізації біоінспірованого методу м'якого декодування лінійних блокових кодів
}

Обгрунтована доиільність застосування м'якого декодування лінійних блокових кодів. Проведено аналіз існуючих методів декодування даних кодів. Розглянуто загальні принципи біоінспірованого підходу до м'якого декодування лінійних блокових кодів. Розроблено алгоритм біоінспірованого декодування лінійних блокових кодів та визначено особливості його реалізачії.

Ключові слова: блокові коди, м’яке декодування, програмна реалізація, біоінспірований підхід, телекомунікаційні технологіï.

\begin{abstract}
Постановка проблеми та аналіз літератури

Важливою складовою багатьох
телекомунікаційних технологій є лінійні блокові коди, що використовуються для забезпечення заданої достовірності передачі інформації. М'яке декодування даних кодів дозволяє збільшити ефективність їх застосування, але характеризується більшою обчислювальною складністю у порівнянні з жорстким декодуванням [1].

У [2] запропоновано метод м'якого декодування блокових кодів на основі впорядкованих статистик, що використовує інформацію про надійність прийнятих символів. Через значну обчислювальну складність даний метод декодування можна застосовувати лише до коротких кодів. У [3] подано метод декодування блокових кодів, що для пошуку оцінок переданих кодових слів використовує генетичні алгоритми, які відносяться до методів біоінспірованої пошукової оптимізації. Узагальнення даного підходу, що лежить в основі декодування відносно довгих лінійних блокових кодів, подано у [4]. При цьому актуальним завданням $\epsilon$ розгляд питань, пов'язаних 3 програмною реалізацією біоінспірованого методу декодування блокових кодів.
\end{abstract}

\begin{tabular}{l}
\hline Мета статті \\
\hline Визначення шляхів та особливостей програмної \\
реалізації біоінспірованого методу декодування \\
лінійних блокових кодів для забезпечення його \\
ефективного застосування у телекомунікаційних \\
технологіях.
\end{tabular}

() О. С. Жученко, С. І. Приходько, М. А. Штомпель, 2017

\section{Основна частина}

У [4] показано, що задача м'якого декодування лінійних блокових кодів у каналі 3 адитивним білим гауссовим шумом полягає у пошуку інформаційної частини біполярного вектора оцінок на основі прийнятого вектора м'яких рішень, що максимізує кореляцію між даними векторами. Формально наведену вище задачу можна подати у вигляді оптимізаційної задачі, що визначається відповідною цільовою функцією та обмеженнями. Аналіз цільової функції та обмежень показав, що сформульована оптимізаційна задача відноситься до класу задач цілочислового нелінійного програмування. Слід зазначити, що розмірність пошуку даної оптимізаційної задачі визначається довжиною інформаційної частини біполярного вектора оцінок. При цьому для відносно довгих лінійних блокових кодів цільова функція характеризується нелінійністю, багатомодальністю та високою розмірністю простору пошуку, що значним чином ускладнює розв'язання даної оптимізаційної задачі.

Враховуючи наявні обмеження існуючих методів декодування лінійних блокових кодів та виходячи 3 наведених особливостей цільової функції та обмежень, пропонується застосовувати узагальнені біоінспіровані процедури для ефективного вирішення сформульованої оптимізаційної задачі. При цьому агентами в даних процедурах виступають біполярні пробні інформаційні вектори, якість яких оцінюється за допомогою фітнес-функції, що, в загальному випадку, може повністю відповідати цільовій функції.

Основні етапи пропонованого біоінспірованого методу м'якого декодування лінійних блокових кодів подано нижче. 
Етап 1. Жорстке декодування прийнятого вектора м'яких рішень.

Етап 2. Знаходження найбільш надійного базису (визначення найбільш надійних позицій у прийнятому векторі м'яких рішень), що обчислюється за допомогою двох перестановок елементів породжувальної матриці лінійного блокового коду.

Етап 3. Пошук 3 використанням узагальнених біоінспірованих процедур пошукової оптимізації біполярного інформаційного вектора, що забезпечує максимальне значення цільової функції.

Етап 4. Формування оцінки переданого кодового слова за допомогою зворотного відображення.

У процесі декодування відповідно до запропонованого методу спочатку здійснюється жорстке рішення на основі прийнятого вектора м'яких рішень, у результаті якого формується відповідний біполярний вектор. Якщо перевірочна умова виконується для кожного елемента прийнятого вектора, то приймається рішення, що даний вектор $€$ переданим біполярним кодовим словом та процес декодування завершується. В противному випадку здійснюється формування найбільш надійного базису шляхом модифікації вихідної породжувальної матриці лінійного блокового коду на основі перестановок і1і елементів відповідно до надійності прийнятих символів. Далі 3 використанням узагальнених біоінспірованих процедур серед групи пробних інформаційних біполярних векторів здійснюється пошук вектора, що забезпечує найбільше значення цільової функції. Пошук закінчується визначенням найбільш імовірної інформаційної частини (та відповідного біполярного кодового слова) після досягнення максимальної кількості ітерацій. Процес декодування завершується зворотним відображенням знайденого вектора у найбільш ймовірне передане біполярне кодове слово [4].

Схему біоінспірованого методу м'якого декодування лінійних блокових кодів, що забезпечує візуалізацію основних його етапів та кроків, подано на рис. 1 .

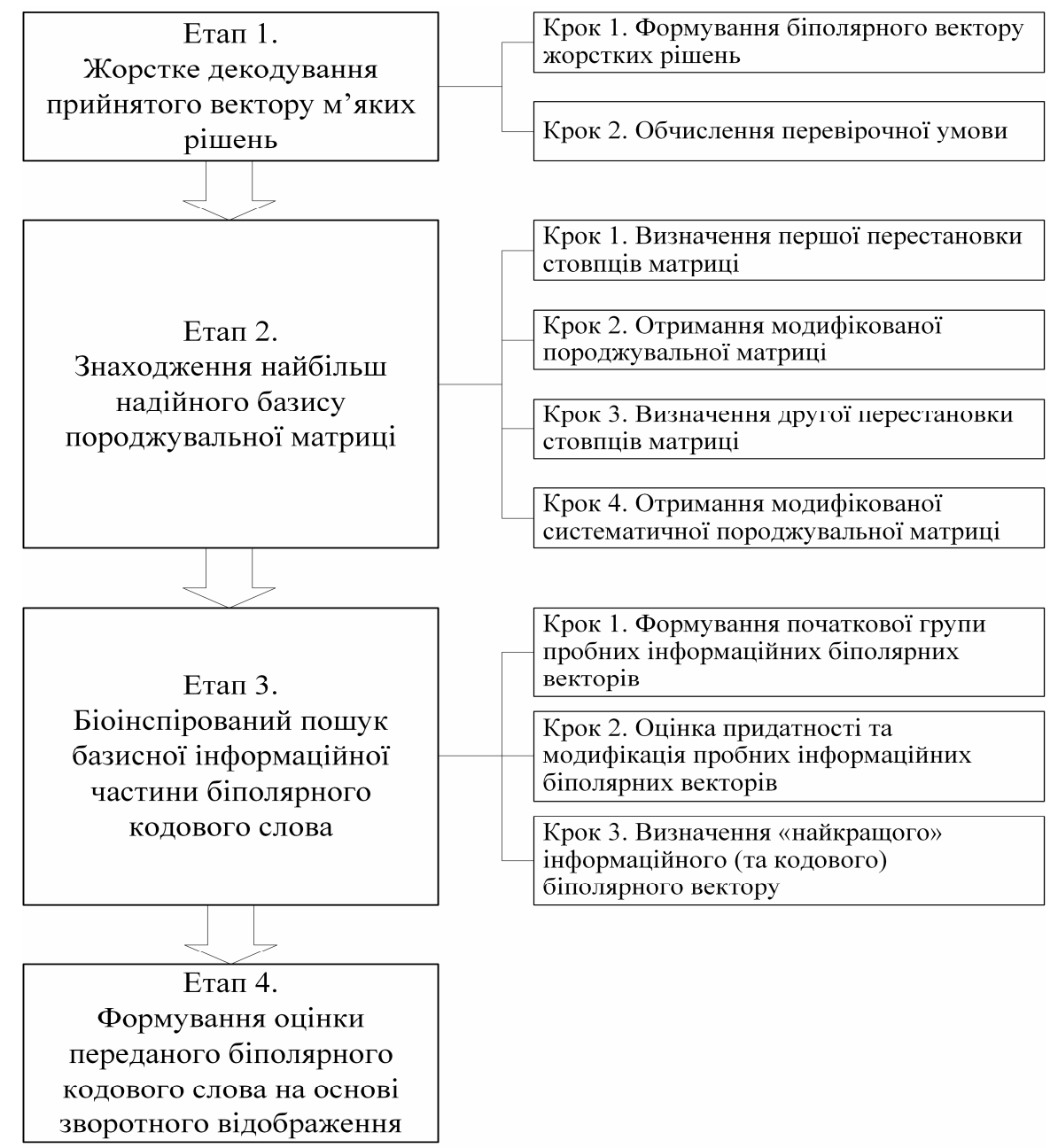

Рис. 1. Схема біоінспірованого методу м'якого декодування лінійних блокових кодів на основі породжувальної матриці 
3 рис. 1 випливає, що відмінною рисою обчислювальна складність запропонованого методу запропонованого методу декодування лінійних декодування в основному визначається типом блокових кодів $€$ застосування узагальненого застосовуваної біоінспірованої процедури та пї біоінспірованого пошуку для визначення найбільш параметрами. Тому вибір конкретної процедури імовірного базисного інформаційного вектора та біоінспірованого пошуку повинен здійснюватися в відповідного біполярного кодового слова. Інші етапи залежності від параметрів коду, характеристик каналу розробленого методу декодування можуть бути зв'язку, вимог до ефективності декодування тощо.

реалізовані як у [2 - 4], при цьому для прискорення В основі програмної реалізації запропонованого знаходження найбільш надійного базису методу декодування лінійних блокових кодів лежить породжувальної матриці доцільно застосовувати розроблений алгоритм, схему якого подано на рис. 2. підхід, розглянутий у [2]. Таким чином,

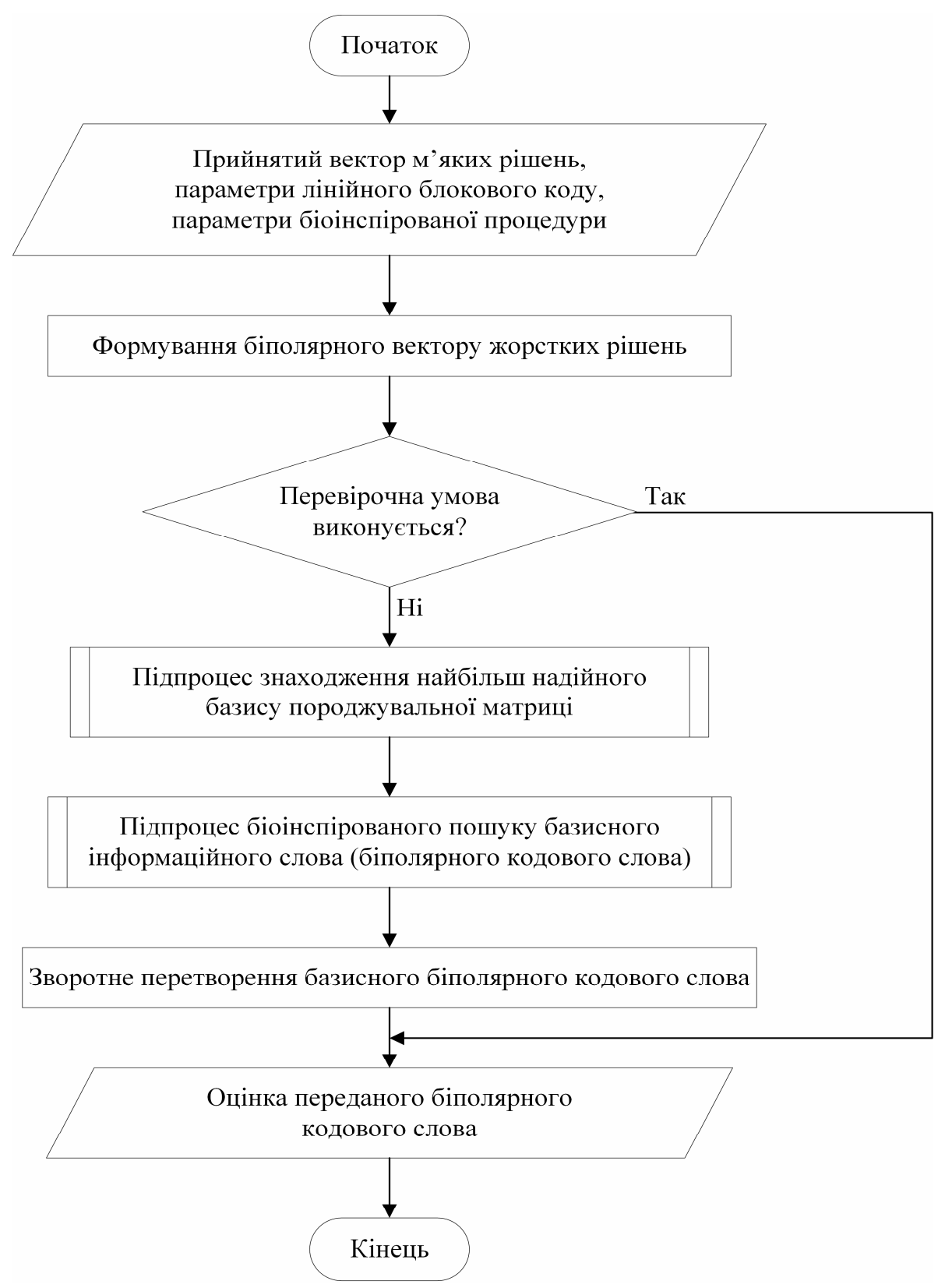

Рис. 2. Схема алгоритму біоінспірованого м’якого декодування лінійних блокових кодів на основі породжувальної матриці 
І Н Ф О Р М А Ц Й Н О - КЕ Р У Ю Ч І С И С ТЕ МИ Н А З А Л І З Н ИЧ Н О М У Т Р А Н С П О Р Т І

Як випливає з рис. 2, у даному алгоритмі вхідними даними $€$ інформація про прийнятий вектор м'яких рішень, параметри використовуваного лінійного блокового коду та параметри обраної біоінспірованої процедури. Відповідно до даного алгоритму спочатку здійснюється спроба здійснення декодування 3 використанням лише біполярного вектора жорстких рішень. Далі у разі необхідності відбувається перехід до м'якого декодування, що містить два підпроцеси підпроцес знаходження найбільш надійного базису породжувальної матриці та підпроцес біоінспірованого пошуку базисного інформаційного слова (та відповідного біполярного кодового слова). Декодування завершується зворотнім перетворенням знайденого базисного біполярного кодового слова. Виходом даного алгоритму $\epsilon$ оцінка найбільш ймовірного біполярного кодового слова, що обирається у ролі переданого кодового слова.

Особливості реалізації ключових підпроцесів алгоритму біоінспірованого м'якого декодування лінійних блокових кодів наведено нижче.

Вхідними даними для підпроцесу знаходження найбільш надійного базису породжувальної матриці служать прийнятий вектор м'яких рішень та параметри використовуваного лінійного блокового коду. Спочатку здійснюється сортування елементів прийнятого вектора у порядку зменшення їх надійності, що визначається абсолютним значенням даних елементів. Далі можна виділити два процеси, що спрямовані на отримання модифікованої інформаційної частини кодового слова та модифікацію породжувальної матриці лінійного блокового коду 3 урахуванням надійності прийнятих символів. У результаті виконання даного підпроцесу формуються такі вихідні дані - первинний базисний вектор м'яких рішень, первинний базисний інформаційний вектор та найбільш надійний базис породжувальної матриці.

Вихідні дані підпроцесу знаходження найбільш надійного базису породжувальної матриці разом 3 параметрами обраної біоінспірованої процедури використовуються як вхідні дані для підпроцесу біоінспірованого пошуку базисного інформаційного слова (біполярного кодового слова).

Даний підпроцес являє собою ітеративну процедуру, що виконується до досягнення максимальної кількості ітерацій та спрямована на знаходження базисних біполярних інформаційного вектора та кодового слова. Для цього спочатку створюється початкова група пробних біполярних інформаційних векторів, що складається 3 первинного базисного інформаційного вектора та заданої кількості близьких до нього випадкових векторів. Далі здійснюється оцінка якості інформаційних векторів шляхом обчислення відповідної цільової функції, що використовує інформацію про найбільш надійний базис породжувальної матриці. Потім відбувається модифікація інформаційних векторів шляхом застосування міграційних операторів обраної біоінспірованої процедури задане число разів. Наприкінці роботи даного підпроцесу формується «найкраще» базисне інформаційне слово (біполярне кодове слово), що в подальшому використовується в основному алгоритмі біоінспірованого м'якого декодування лінійних блокових кодів.

\section{Висновки}

При м'якому декодуванні відносно довгих лінійних блокових кодів доцільно використовувати біоінспірований підхід 3 урахуванням інформації про надійність прийнятих символів. Для забезпечення ефективного застосування біоінспірованого методу декодування лінійних блокових кодів у телекомунікаційних технологіях розроблено схему відповідного алгоритму та визначено особливості його реалізації.

\section{Література}

1. Морелос-Сарагоса, Р. Искусство помехоустойчивого кодирования. Методы, алгоритмы, применение [Текст]: пер. с англ. / Р. Морелос-Сарагоса. - М.: Техносфера, 2005. $320 \mathrm{c}$.

2. Fossorier, M. P. C. Soft-Decision Decoding of Linear Block Codes Based on Ordered Statistics / M.P.C. Fossorier, S. Lin // , IEEE Transactions on Information Theory. - 1995. - Vol. 41, № 5. September. - P. 1379 - 1396.

3. Berbia, H. Genetic Algorithm for Decoding Linear Codes over AWGN and Fading Channels / H. Berbia, F. Elbouanani, R. Romadi, H. Benazza, M. Belkasmi // Journal of Theoretical and Applied Information Technology. - 2011. - Vol. 30, № 1. - P. 35 - 41.

4. Жученко, А. С. Метод декодирования линейных блоковых кодов на основе популяционных процедур поисковой оптимизации [Текст] / А. С. Жученко, Н. Г. Панченко, С. В. Панченко, Н. А. Штомпель // Інформаційно-керуючі системи на залізничному транспорті: науково-технічний журнал. - Харків: УкрдУЗТ, 2016. - Вип. 2 (117). C. $25-29$.

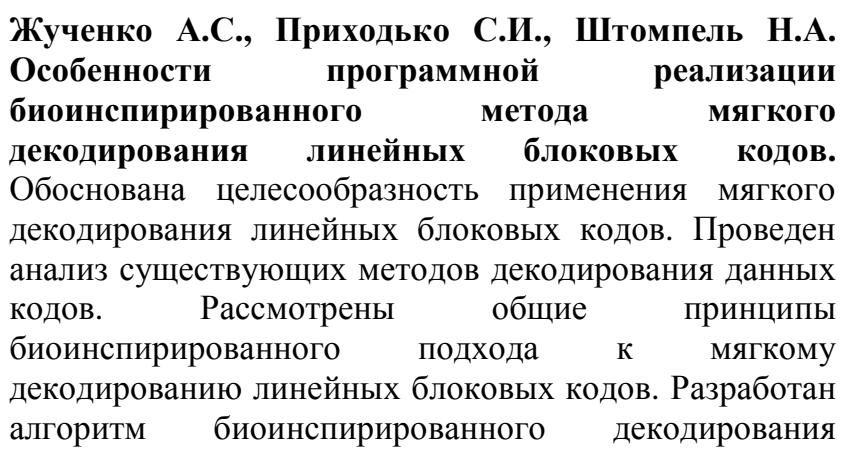


линейных блоковых кодов и определены особенности его реализации.

Ключевые слова: блоковые коды, мягкое декодирование, программная реализация, биоинспирированный подход, телекоммуникационные технологии.

Zhuchenko O., Prihodko S., Shtompel M. Software implementation features of bioinspired method of soft decoding linear block codes. The important part of many telecommunication technologies are linear block codes. The use of soft decoding can increasing the effectiveness of these codes. The expediency of application bioinspired approach for soft decoding relatively long linear block codes is grounded. The general principles bioinspired approach to soft decoding of linear block codes is considered. The basic steps and flowchart of the bioinspired method of decoding linear block codes are presented. A distinctive feature of the proposed method of decoding linear block codes is the use of generalized bioinspired search to determine the most likely base information vector and corresponding bipolar codeword. It is noted that the choice of a particular procedure bioinspired search should be carried out according to the parameters of the code, channel characteristics and performance requirements decoding. The ways of software implementation bioinspired method of decoding linear block codes are determined. Bioinspired decoding algorithm for linear block codes and features its implementation are presented. The list of input and output data for this algorithm is presented. Principles of the subprocess of the most reliable basis generative matrix and subprocess bioinspired search basic information word (and the corresponding bipolar codeword) are presented.

Keywords: block codes, soft decoding, software implementation, bioinspired approach, telecommunication technologies.

Надійшла 30.03.2017p.

Жученко Олександр Сергійович, кандидат технічних наук, доиент, доцент кафедри транспортного зв'язку Украӥнського державного університету залізничного транспорту, Харків, Україна. E-mail: tz@kart.edu.иа.

Приходько Сергій Іванович, доктор технічних наук, професор, проректор з науково-педагогічної роботи Украӥнського державного університету залізничного транспорту, Харків, Україна. E-mail: tz@kart.edu.иа.

Штомпель Микола Анатолійович, кандидат технічних наук, доцент, доцент кафедри транспортного зв'язку Українського державного університету залізничного транспорту, Харків, Україна. E-mail: shtompel.mykola@kart.edu.ua.
Zhuchenko O., Candidate of Sciences (Technology), Associate Professor (Docent), Associate Professor at the Department of Transport Communication, Ukrainian State University of Railway Transport, Kharkiv, Ukraine. E-mail: tz@kart.edu.ua.

Prihodko S., Vice-rector for scientific and pedagogical work of Ukrainian State University of Railway Transport, Doctor of Technical Sciences, professor, Ukrainian State University of Railway Transport, Kharkiv, Ukraine. E-mail: tz@kart.edu.ua.

Shtompel M., Candidate of Sciences (Technology), Associate Professor (Docent), Associate Professor at the Department of Transport Communication, Ukrainian State University of Railway Transport, Kharkiv, Ukraine. E-mail: shtompel.mykola@kart.edu.ua. 